\title{
Dopamine-Stimulated Dephosphorylation of Connexin 36 Mediates AII Amacrine Cell Uncoupling
}

\author{
W. Wade Kothmann, Stephen C. Massey, and John 0'Brien \\ Richard S. Ruiz Department of Ophthalmology and Visual Science, University of Texas Medical School at Houston, Houston, Texas 77030
}

Gap junction proteins form the substrate for electrical coupling between neurons. These electrical synapses are widespread in the CNS and serve a variety of important functions. In the retina, connexin 36 (Cx36) gap junctions couple AII amacrine cells and are a requisite component of the high-sensitivity rod photoreceptor pathway. AII amacrine cell coupling strength is dynamically regulated by background light intensity, and uncoupling is thought to be mediated by dopamine signaling via $\mathrm{D}_{1}$-like receptors. One proposed mechanism for this uncoupling involves dopamine-stimulated phosphorylation of $\mathrm{Cx} 36$ at regulatory sites, mediated by protein kinase A. Here we provide evidence against this hypothesis and demonstrate a direct relationship between $\mathrm{Cx} 36$ phosphorylation and AII amacrine cell coupling strength. Dopamine receptor-driven uncoupling of the AII network results from protein kinase A activation of protein phosphatase $2 \mathrm{~A}$ and subsequent dephosphorylation of $\mathrm{Cx} 36$. Protein phosphatase 1 activity negatively regulates this pathway. We also find that $\mathrm{Cx} 36$ gap junctions can exist in widely different phosphorylation states within a single neuron, implying that coupling is controlled at the level of individual gap junctions by locally assembled signaling complexes. This kind of synapse-by-synapse plasticity allows for precise control of neuronal coupling, as well as cell-type-specific responses dependent on the identity of the signaling complexes assembled.

\section{Introduction}

Electrical synapses formed by gap junctions between neurons underlie a number of important neural functions, including neuronal synchronization (Deans et al., 2001), signal averaging (DeVries et al., 2002), and network oscillations (Hormuzdi et al., 2001; Buhl et al., 2003), in addition to providing an alternative form of synaptic connection with properties that differ distinctly from the more common chemical synapses. Connexin 36 (Cx36) is the most widely expressed gap junction protein in neurons (Connors, 2009), but little is known about how intercellular coupling mediated by $\mathrm{Cx} 36$ is regulated. Loss of $\mathrm{Cx} 36$ eliminates electrical coupling and coordinated output in certain cortical interneurons (Deans et al., 2001), impairs gamma frequency oscillations in hippocampus (Hormuzdi et al., 2001; Buhl et al., 2003), causes deficits in cerebellar motor learning (Van Der Giessen et al., 2008), and eliminates the high-gain rod photoreceptor pathway (Güldenagel et al., 2001; Deans et al., 2002; Völgyi et al., 2004). Cx36 is also the dominant connexin in pancreatic $\beta$ cells (Serre-Beinier et al., 2008), and loss of these gap junctions causes insulin secretion abnormalities that resemble those observed in type 2 diabetes (Wellershaus et al., 2008). Thus, understanding the regulation of $\mathrm{Cx} 36$ channel function is of critical importance

Received July 16, 2009; revised Sept. 24, 2009; accepted 0ct. 16, 2009.

This research was supported by National Research Service Award Fellowship NS63534 (W.W.K.), National Institutes of Health (NIH) Grants EY12857 (J.0.) and EY06515 (S.C.M.), NIH Core GrantEY10608, and a Research to Prevent Blindness grant to the Department of Ophthalmology and Visual Science. We thank H. Hoshi and W.-L. Liu for assistance with surgeries and $\mathrm{S}$. Mills for many helpful discussions.

Correspondence should be addressed to Wade Kothmann, University of Texas Medical School at Houston, 6431 Fannin, Houston, TX 77030. E-mail: Wade.Kothmann@gmail.com.

DOI:10.1523/JNEUROSCI.3436-09.2009

Copyright $\odot 2009$ Society for Neuroscience 0270-6474/09/2914903-09\$15.00/0 to understanding brain and sensory system function as well as endocrine function.

The retina is an ideal tissue for studying regulation of gap junction-mediated coupling; every class of retinal neuron expresses gap junction proteins (Bloomfield and Völgyi, 2009), and the tissue remains physiologically intact when isolated from the eye. In mammalian retina, the AII amacrine cell, which receives input from rod bipolar cells (Strettoi et al., 1990) and is critical for rod-mediated vision (Güldenagel et al., 2001; Deans et al., 2002; Völgyi et al., 2004), is a well established model for studying Cx36mediated coupling (Famiglietti and Kolb, 1975; Mills and Massey, 1995; Feigenspan et al., 2001; Mills et al., 2001; Veruki and Hartveit, 2002; Xia and Mills, 2004; Veruki et al., 2008). AII amacrine cells are extensively coupled to each other by Cx36 gap junctions under scotopic background light and are uncoupled in response to photopic background light (Bloomfield et al., 1997; Bloomfield and Völgyi, 2004), dopamine $\mathrm{D}_{1}$-like receptor $\left(\mathrm{D}_{1} \mathrm{R}\right)$ activation (Hampson et al., 1992), and protein kinase A (PKA) activation (Mills and Massey, 1995; Urschel et al., 2006). Studies in cell cultures have identified two phosphorylation sites on the fish homolog of Cx36, Ser110, and Ser276 (Ser293 in mammals) that are required for regulation of $\mathrm{Cx} 36$-mediated coupling by PKA (Ouyang et al., 2005). These sites have been shown to undergo dynamic changes in phosphorylation state in the retina (Kothmann et al., 2007). We therefore sought to determine the relationship between $\mathrm{Cx} 36$ phosphorylation and regulation of Cx36-mediated coupling by using the well described AII amacrine cell system.

\section{Materials and Methods}

Intracellular injection. Care and use of experimental animals was performed in accordance with institutional guidelines at the University of 
Texas Health Science Center at Houston. All experiments were performed on light-adapted animals in the daytime phase of their light cycle. Adult rabbits were anesthetized with urethane $(1.5 \mathrm{~g} / \mathrm{kg}$, i.p.), and the eyes removed into Ames medium bubbled with $95 \% \mathrm{O}_{2} / 5 \% \mathrm{CO}_{2}$. After this, the animals were killed by intracardial injection with an overdose of urethane. The superior portion of the retina was separated into several retina-sclera pieces, which were then incubated with 4,6-diamino-2phenylindole (Invitrogen) for $20 \mathrm{~min}$ to label cell nuclei [this short incubation labels AII amacrine cells preferentially (Mills and Massey, 1991)]. Immediately before each piece was to be injected, the retina was isolated and mounted photoreceptor-side down on black nitrocellulose filters. Neurobiotin (3.5\%; Vector Laboratories) was injected by iontophoresis $( \pm 1 \mathrm{nA}, 3 \mathrm{~Hz})$ into AII amacrine cells, as described previously in detail (Xia and Mills, 2004), except that Alexa 488-conjugated biocytin (Invitrogen) was used to visualize the microelectrode. Injections were performed for $5 \mathrm{~min}$ on an Olympus BX51WI microscope; this was followed by a $15 \mathrm{~min}$ diffusion period. Each piece was superfused, starting $15 \mathrm{~min}$ before the start of the injection and on through the diffusion period, with either bubbled Ames medium $\left(\right.$ at $35^{\circ} \mathrm{C}$ ) or Ames medium containing $\mathrm{D}_{1} \mathrm{R}$ agonist (SKF38393 [( \pm )-1-phenyl-2,3,4,5-tetrahydro(1H)-3-benzazepine-7,8-diol hydrobromide], 10 or $100 \mu \mathrm{M}$ ) or antagonist $\quad(\mathrm{SCH} 23390 \quad[R(+)$-7-chloro-8-hydroxy-3-methyl-1-phenyl2,3,4,5-tetrahydro- $1 \mathrm{H}$-3-benzazepine hydrochloride], 10 or $100 \mu \mathrm{M}$ ). After tracer injection and diffusion periods, the pieces of retina were fixed for $15 \mathrm{~min}$ in $4 \%$ formaldehyde in $0.1 \mathrm{~m}$ phosphate buffer and subsequently immunolabeled for Cx36 and phospho-Ser293-Cx36 (Kothmann et al., 2007). Dopaminergic drugs were purchased from Tocris Bioscience.

Pharmacology experiments. Rabbit eyecups with the vitreous removed were separated into superior and inferior portions by chopping along the myelinated band with a razor blade. The central portion of the superior part from a single eye was then further separated into four adjacent retina-sclera pieces. Each retina-sclera piece was incubated for $20 \mathrm{~min}$ in bubbled Ames medium (at $35^{\circ} \mathrm{C}$ ) with the appropriate pharmacologic agent. Thus, each experiment yielded one control piece and three matched pieces subjected to various pharmacological treatments. After the incubation period, the retina-sclera pieces were fixed for $15 \mathrm{~min}$ in $4 \%$ formaldehyde in $0.1 \mathrm{~m}$ phosphate buffer, after which the retina was isolated, mounted photoreceptor-side down on nitrocellulose filters, and immunolabeled for Cx36 and phospho-Ser293-Cx36. The cAMP analogs were purchased from Axxora, the microcystin-LR was from Calbiochem, and the tautomycetin was from Tocris Bioscience.

Immunolabeling. Isolated retina pieces (photoreceptor-side down on nitrocellulose filters) were first blocked overnight at $10^{\circ} \mathrm{C}$ in immunolabeling buffer (PBS with $0.5 \%$ Triton $\mathrm{X}-100$ and $0.1 \% \mathrm{NaN}_{3}$, $\mathrm{pH} 7.4$ ) with $10 \%$ normal donkey serum (Jackson ImmunoResearch). Pieces were then labeled with monoclonal mouse anti-Cx36 (mCx36, 1:1000 dilution; Millipore Bioscience Research Reagents) and rabbit anti-phosphoSer293-Cx36 (Ser293-P, 1:1000 dilution) (Kothmann et al., 2007) antibodies in immunolabeling buffer with $10 \%$ donkey serum for $5 \mathrm{~d}$ at $10^{\circ} \mathrm{C}$. Retina pieces from pharmacology experiments were also labeled with goat anti-calretinin antibodies (1:5000 dilution; Millipore Bioscience Research Reagents) to label AII amacrine cells. After extensive washing, retina pieces were labeled with secondary antibodies (1:500 dilutions) in immunolabeling buffer with $5 \%$ donkey serum overnight at $10^{\circ} \mathrm{C}$. For retina pieces from injection experiments, anti-calretinin labeling was replaced with Alexa 488-conjugated streptavidin (1:250 dilution) to label Neurobiotin in the injected network. Alexa 488-conjugated streptavidin and secondary antibodies were purchased from Invitrogen. All other secondary antibodies were cyanine 3 or cyanine 5 conjugated (Jackson ImmunoResearch). Retina pieces were whole mounted on slides with Vectashield (Vector Laboratories).

Imaging and data quantification. Images were collected on a Zeiss LSM 510 Meta confocal microscope using a $63 \times(1.4$ numerical aperture) or $40 \times$ (1.3 numerical aperture) oil-immersion objectives. Imaging settings in the LSM software were identical when comparisons are made. Coupling between AII amacrine cells was quantified as the diffusion coefficient for Neurobiotin tracer transfer using a two-dimensional compartmental diffusion model (Xia and Mills, 2004). Cx36 phosphorylation was quantified as the ratio of the mean intensity of Ser293-P to mCx36 immunofluores- cence at individual regions of interest (ROIs), each identified by the $\mathrm{mCx} 36$ label as a single $\mathrm{Cx} 36$ gap junction plaque. ROI identification was accomplished using SimplePCI software (Compix) to analyze single optical sections. ROI borders were defined by a $20 \%$ intensity threshold in the $\mathrm{mCx} 36$ channel and a size threshold of $0.15 \mu \mathrm{m}^{2}$. For the pharmacology experiments, an additional, empirically determined intensity threshold was added in the calretinin channel to include only the Cx36 gap junctions localized on the AII network. In our hands, this represents $96 \%$ of the Cx36 gap junctions in stratum 5 of the rabbit inner plexiform layer, in good agreement with a previously reported value of $98 \%$ (Mills et al., 2001). In the case of injected AII networks, single optical sections were collected focused on the distal dendrites of the injected cell, and all gap junctions in the field of view were included. Because $96-98 \%$ of the gap junctions at this focus depth in the retina are on AIIs, even when Neurobiotin diffusion was weak, there was a very low probability of including Cx36 plaques that were not on AII amacrine cells.

In the pharmacology experiments, six images were collected at midperipheral eccentricity from each condition; in the injection experiments, three images were collected on different sides of each injected cell. The ratio of the mean intensity of Ser293-P to mCx36 immunofluorescence was calculated for each ROI and averaged across all ROIs in all images per condition. In this way, we collapsed the phosphorylation data into one value per condition per animal to perform statistical analysis.

To calculate the fraction of Cx36 plaques that showed any detectable phospho-Ser293 antibody labeling, regardless of its intensity, we first measured the background labeling in the Ser293-P channel for all images (measured in areas in which no mCx36 labeling existed). We then set a threshold for detectable labeling at $200 \%$ of the mean background value (this value approximated the mean $+2 \mathrm{SD}$ of the background levels observed in the initial experiments). Any Cx36 gap junction plaque with Ser293-P labeling above this threshold was considered "detectably phosphorylated" for purposes of calculating the fraction of plaques showing phosphorylation.

Images presented in the figures were collected using identical settings in the LSM software. Processing was limited to application of a $10 \%$ intensity threshold in all channels to minimize background noise.

Statistical analysis. A linear regression was used to find the correlation between relative Cx36 phosphorylation and AII amacrine cell coupling. Unpaired, two-tailed $t$ tests were used to compare each drug-treated condition with the control condition from the same animal. Unpaired, two-tailed $t$ tests were also used to compare two drug-treated conditions that shared one common drug (such as $\mathrm{D}_{1} \mathrm{R}$ agonist condition vs $\mathrm{D}_{1} \mathrm{R}$ agonist plus phosphatase inhibitor).

\section{Results}

\section{AII amacrine cell uncoupling is associated with dephosphorylation of $\mathrm{Cx} 36$}

We combined intracellular injection of the Cx36-permeant tracer Neurobiotin with immunolabeling for phospho-Ser293-Cx36 to measure AII amacrine cell coupling and Cx36 phosphorylation in isolated rabbit retina. As reported previously (Hampson et al., 1992), AII-AII coupling was modulated by dopamine signaling (Fig. 1 A$C)$. Activation of $\mathrm{D}_{1} \mathrm{Rs}(\mathrm{SKF} 38393,10 \mu \mathrm{M})$ reduced AII-AII coupling (Fig. $1 B$ ), whereas antagonism of $\mathrm{D}_{1}$ Rs (SCH23390, $\left.100 \mu \mathrm{M}\right)$ increased coupling (Fig. 1C). Phosphorylation of Cx36 at Ser293 (Ser293-P) was assessed at gap junctions on the injected AII amacrine cell dendrites and those nearby (Fig. $1 D-F$ ) (see Materials and Methods). Ser293-P was decreased by $\mathrm{D}_{1} \mathrm{R}$ activation (Fig. $1 \mathrm{H}$ ) relative to control (Fig. $1 G$ ). Consistent with this, $\mathrm{D}_{1} \mathrm{R}$ antagonism increased Ser293-P (Fig. 1I). To quantify AII amacrine cell coupling, we used a compartmental diffusion model to estimate the diffusion coefficient of the Neurobiotin tracer (Xia and Mills, 2004). We quantified Ser293-P as a ratio of the mean fluorescence intensity of the phospho-Ser293-Cx36 antibody to the mean fluorescence intensity of a monoclonal Cx36 antibody at each individual gap junction plaque (for full details, see Materials and Methods). 

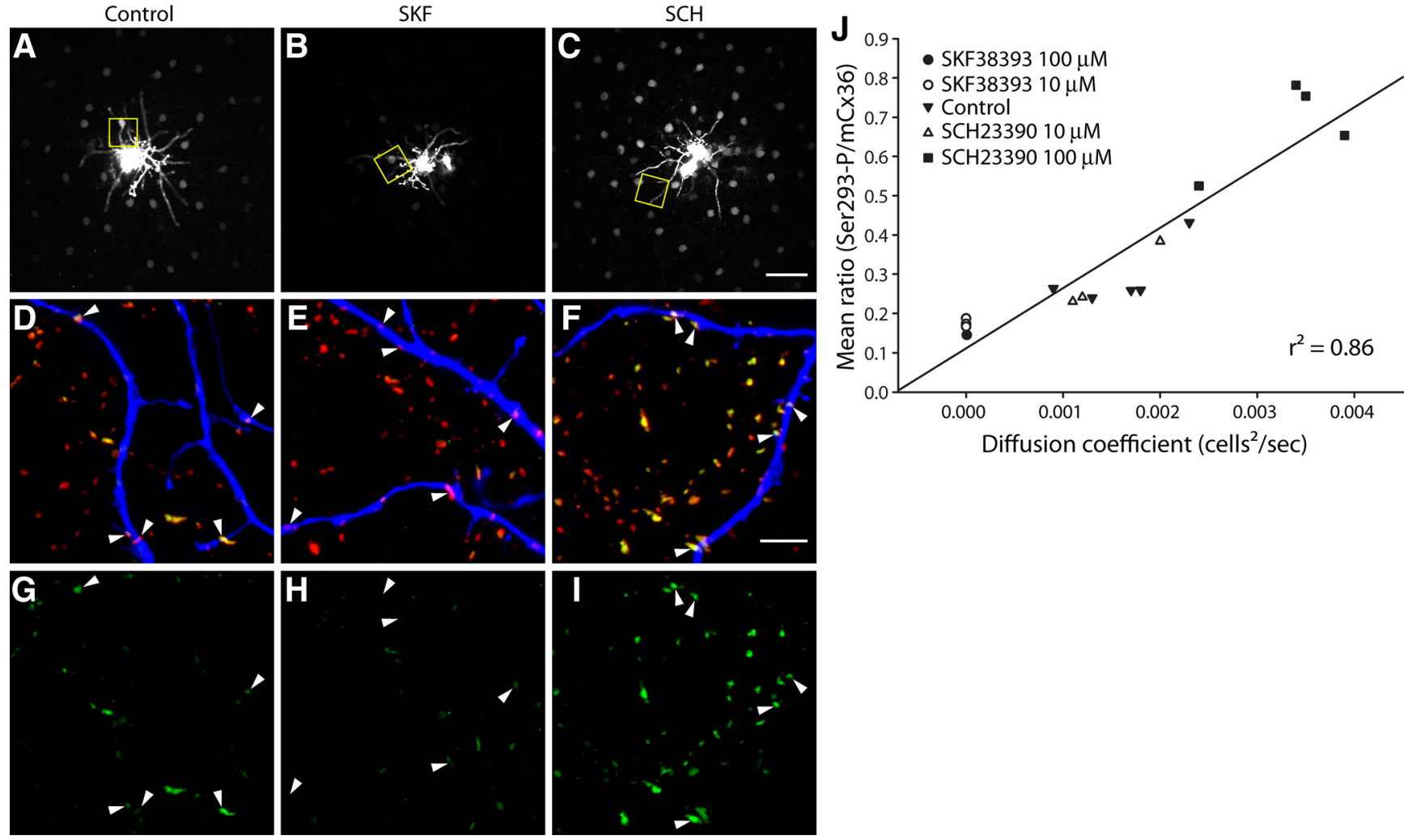

Figure 1. All amacrine cell coupling is directly related to $C \times 36$ phosphorylation at Ser293. $A-C$, Neurobiotin tracer coupling between All amacrine cells is modulated by dopamine $D_{1} R$ signaling. $D_{1} R$ activation $\left[\boldsymbol{B} ;\right.$ SKF38393 (SKF), $10 \mu \mathrm{m}$ ] reduced the extent of Neurobiotin diffusion relative to control (A). $D_{1} R$ antagonism [C; $S C H 23390$ (SCH), $\left.100 \mu \mathrm{m}\right]$ increased tracer diffusion. Images are mini-stacks ( $2 \mu \mathrm{m}$ in $z$-depth) focused on the somas of the All amacrine cells. Yellow boxes highlight areas shown in $\boldsymbol{D}-\boldsymbol{I}$ (at different focal depth). D-F, Cx36 gap junctions, labeled with $\mathrm{m}$ (x36 antibody (red) and Ser293-P antibody (green), on and around the dendrites of the injected All amacrine cell, labeled with fluorophore-conjugated streptavidin (blue). The CX36 gap junctions not on the injected cell are primarily on other All amacrine cells (see Materials and Methods). Arrowheads identify prominent $\mathrm{Cx36}$ gap junctions on the injected cells. G-I, Phosphorylation of (x36 at Ser293, a site known to regulate coupling through (x36 gap junctions (Ouyang et al., 2005), is also modulated by dopamine $D_{1} R$ signaling. Arrowheads identify the locations of the same Cx36 gap

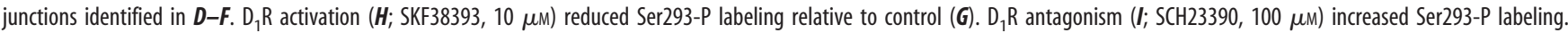
$J$, Quantification of the relationship between All amacrine cell coupling and Cx36 phosphorylation at Ser293. The mean ratio of Ser293-P intensity to $m$ Cx36 intensity (across all Cx36 gap junctions in 3 images per injection) is plotted against the diffusion coefficient for Neurobiotin tracer transfer calculated for each injected All amacrine cell network. The strong correlation of the data $\left(r^{2}=0.86\right)$ indicates a direct relationship between All amacrine cell coupling and Cx36 phosphorylation at Ser293. Images are 2- $\mu \mathrm{m}$-deep stacks. Scale bars: $\boldsymbol{C}, 50 \mu \mathrm{m} ; \boldsymbol{F}, 5 \mu \mathrm{m}$.

We collected three images focused on the dendrites of each injected AII amacrine cell, calculated the mean Ser293-P for all Cx36 plaques detected across all three images, and plotted this against the diffusion coefficient for Neurobiotin tracer transfer measured for that AII amacrine network (Fig. $1 \mathrm{~J}$ ). A strong correlation $\left(r^{2}=0.86\right)$ was found between AII amacrine cell coupling and Cx36 phosphorylation at Ser293. Because Ser293 is known to regulate coupling through $\mathrm{Cx} 36$ gap junctions (Ouyang et al., 2005), this finding leads us to conclude that phosphorylation at this site increases coupling.

\section{$D_{1} R$-stimulated dephosphorylation of $\mathrm{Cx} 36$ is mediated by PKA}

The canonical $D_{1} R$ signaling pathway involves a $G_{s}$-protein that activates adenylyl cyclase, thereby elevating $[\mathrm{cAMP}]_{\mathrm{i}}$ to activate PKA (Neve et al., 2004). We therefore examined the role of PKA activity in controlling Cx36 phosphorylation state downstream of $\mathrm{D}_{1} \mathrm{R}$ signaling using retina-sclera preparations (Fig. 2) (see Materials and Methods). $\mathrm{D}_{1} \mathrm{R}$ activation (SKF38393, $100 \mu \mathrm{M}$ ) caused a 3.5-fold reduction in Ser293-P intensity (Fig. 2D). Inhibition of PKA (Rp-8-CPT-cAMPS, $20 \mu \mathrm{M}$ ) significantly suppressed the effect of $\mathrm{D}_{1} \mathrm{R}$ activation (Fig. $2 \mathrm{~F}$ ), resulting in intermediate $\mathrm{Cx} 36$ phosphorylation that was below control levels but above the levels seen with $\mathrm{D}_{1} \mathrm{R}$ activation alone. $\mathrm{D}_{1} \mathrm{R}$ antago- nism (SCH23390, $100 \mu \mathrm{M})$ caused a twofold increase in Cx36 phosphorylation (Fig. $2 \mathrm{H}$ ). As a second measure of the effects of these treatments, we determined whether they altered the fraction of Cx36 plaques that showed detectable Ser293-P labeling, regardless of fluorescence intensity. Detectable Ser293-P labeling was defined as $200 \%$ of the background fluorescence in that channel (see Materials and Methods); this equated approximately to a 5\% threshold in the Ser293-P channel. This measure yielded results consistent with the mean Ser293-P measurements (Fig. $2 J$ ). Histograms of the ratio of Ser293-P to mCx36 fluorescence from one representative experiment showed that $\mathrm{D}_{1} \mathrm{R}$ activation caused a leftward shift (reduction in Ser293-P) in the population of $\mathrm{Cx} 36$ plaques which was blocked by inhibition of PKA, whereas $D_{1} R$ antagonism caused a rightward shift (increase in Ser293-P) in the Cx36 population (supplemental Fig. S1, available at www.jneurosci.org as supplemental material). These results lead us to conclude that activation of PKA is a component of the pathway regulating Cx36mediated coupling of AII amacrine cells. However, these results are not consistent with direct phosphorylation of Ser293 by PKA, because inhibition of this kinase led to a net increase in Cx36 phosphorylation.

We also tested the effects of dopamine itself on Cx36 phosphorylation at Ser293 in AII amacrine cells. Consistent with 

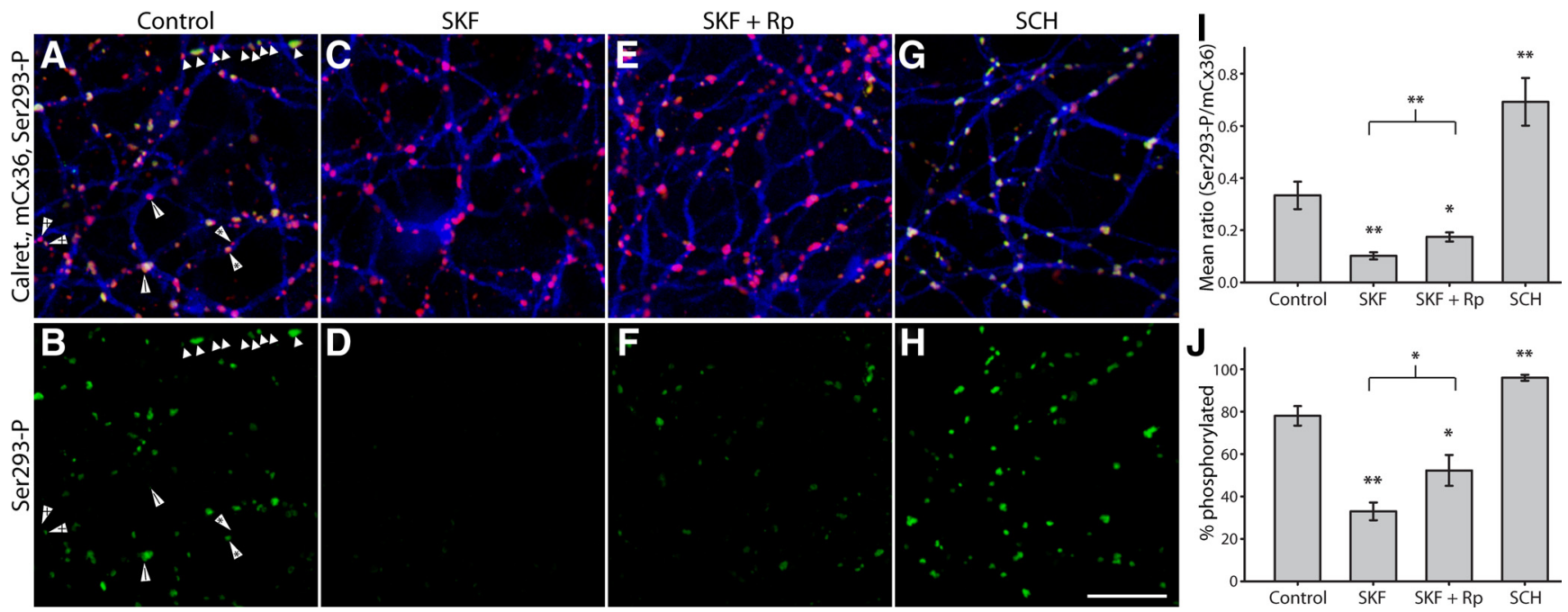

Figure 2. PKA mediates $D_{1}$ R-dependent dephosphorylation of $(x 36$ at Ser293 in All amacrine cells. $\boldsymbol{A}$, $\boldsymbol{B}$, Under control conditions, Ser293-P (green) labeling of Cx36 gap junctions (mCx36, red) on All amacrine cells (calretinin, blue) was heterogeneous. Annotated arrowheads indicate pairs of Cx36 plaques along single dendrites that are in different phosphorylation states. The close proximity of Cx36 plaques with widely varying Ser293-P labeling implies that regulation is locally controlled at individual plaques. C, D, D, R activation (SKF38393, $100 \mu \mathrm{M}$ ) greatly diminished Ser293-P labeling. $\boldsymbol{E}, \boldsymbol{F}$, Inhibition of PKA [Rp-8-CPT-CAMPS (Rp), $20 \mu \mathrm{m}$ ] attenuated the dramatic reduction in Ser293-P labeling caused by SKF38393 (SKF; $100 \mu \mathrm{M}$ ). $\mathbf{G}, \boldsymbol{H}$, Antagonism of $\mathbf{D}_{1}$ Rs [SCH23390 (SCH), $100 \mu \mathrm{m}$ ] increased Ser293-P labeling. I, Summary of data shows that inhibition of PKA significantly suppressed the reduction in Ser293 phosphorylation caused by $D_{1}$ R activation. J, Summary of data shows that changes in the percentage of X 36 plaques that show detectable Ser293-P labeling follows the same pattern established for relative Ser293-P measurements in $I$. Error bars are SEM, $n=6 .{ }^{*} p<0.05,{ }^{* *} p<0.01$. Images are 1- $\mu$ m-deep stacks. Scale bar: $\boldsymbol{H}, 10 \mu \mathrm{m}$.

the effects of $\mathrm{D}_{1} \mathrm{R}$ agonist, dopamine application $(1 \mu \mathrm{M})$ caused a fourfold reduction in Ser293-P intensity (control, mean \pm SEM ratio of $0.41 \pm 0.06$; dopamine, mean \pm SEM ratio of $0.096 \pm 0.02$; $n=4, p<0.01$ ), as well as a similar reduction in the percentage of $\mathrm{Cx} 36$ plaques that showed detectable Ser293-P labeling (control, mean of $69 \pm 6 \%$; dopamine, mean of $19 \pm 8 \% ; n=4, p<0.01$ ) (supplemental Fig. S2, available at www. jneurosci.org as supplemental material). This concentration of dopamine represents the upper end of estimates of the physiological extracellular dopamine concentration in the vertebrate retina (Witkovsky et al., 1993) and is known to strongly uncouple AII amacrine cells (Hampson et al., 1992; Mills and Massey, 1995). Thus, endogenous levels of dopamine should be sufficient to drive dephosphorylation of $\mathrm{Cx} 36$.

Modulation of Cx36 phosphorylation at Ser293 could alter coupling between AII amacrine cells in several ways. It could modulate the permeability of Cx36 gap junctions to the Neurobiotin tracer, stimulate insertion or removal of gap junction proteins from the plasma membrane at each $\mathrm{Cx} 36$ plaque, or cause changes in the number of gap junction plaques between AII amacrine cells. Changes in Ser293-P caused by $\mathrm{D}_{1} \mathrm{R}$ receptor activation (SKF38393, $100 \mu \mathrm{M}$ ) or antagonism (SCH23390, $100 \mu \mathrm{M}$ ) had no effect on the mean plaque size of $\mathrm{Cx} 36$ gap junctions or the mean number of plaques on AII dendrites in a given area (Fig. 3 ). Thus, the changes in tracer coupling between AII amacrine cells presented above cannot be attributed to changes in the trafficking of Cx36 proteins or the number of Cx36 gap junctions connecting AII amacrine cells. Rather, it appears that phosphorylation of Ser293 must modulate the permeability of Cx36 to the Neurobiotin tracer.

\section{PP2A is required for $D_{1} R$-stimulated dephosphorylation of $\mathrm{Cx} 36$}

Because $D_{1} R$ activation reduced Ser293-P, we hypothesized that dopamine signaling increases overall phosphatase activity at Cx36 gap junctions in AII amacrine cells. In eukaryotic cells, protein phosphatase 1 (PP1) and protein phosphatase 2A (PP2A) are the most abundant phosphatases (Virshup and Shenolikar, 2009); thus, we initially targeted these proteins as potential effectors of $\mathrm{D}_{1} \mathrm{R}$-stimulated dephosphorylation of Cx36. We tested the ability of $D_{1} R$ agonist to reduce Ser293-P in the presence of different phosphatase inhibitors at concentrations that preferentially inhibit either PP1 or PP2A. Microcystin-LR (0.5 nM), an inhibitor with higher affinity for PP2A ( $\mathrm{IC}_{50}$ of $40 \mathrm{pM}$ ) than for PP1 ( IC $_{50}$ of $1.7 \mathrm{nM}$ ) (Honkanen et al., 1990), completely blocked the reduction of Ser293-P caused by $D_{1} \mathrm{R}$ activation (SKF38393, $10 \mu \mathrm{M}$ ) (Fig. 4F). Application of microcystin-LR alone significantly increased Ser293-P levels relative to control (Fig. 4H), 

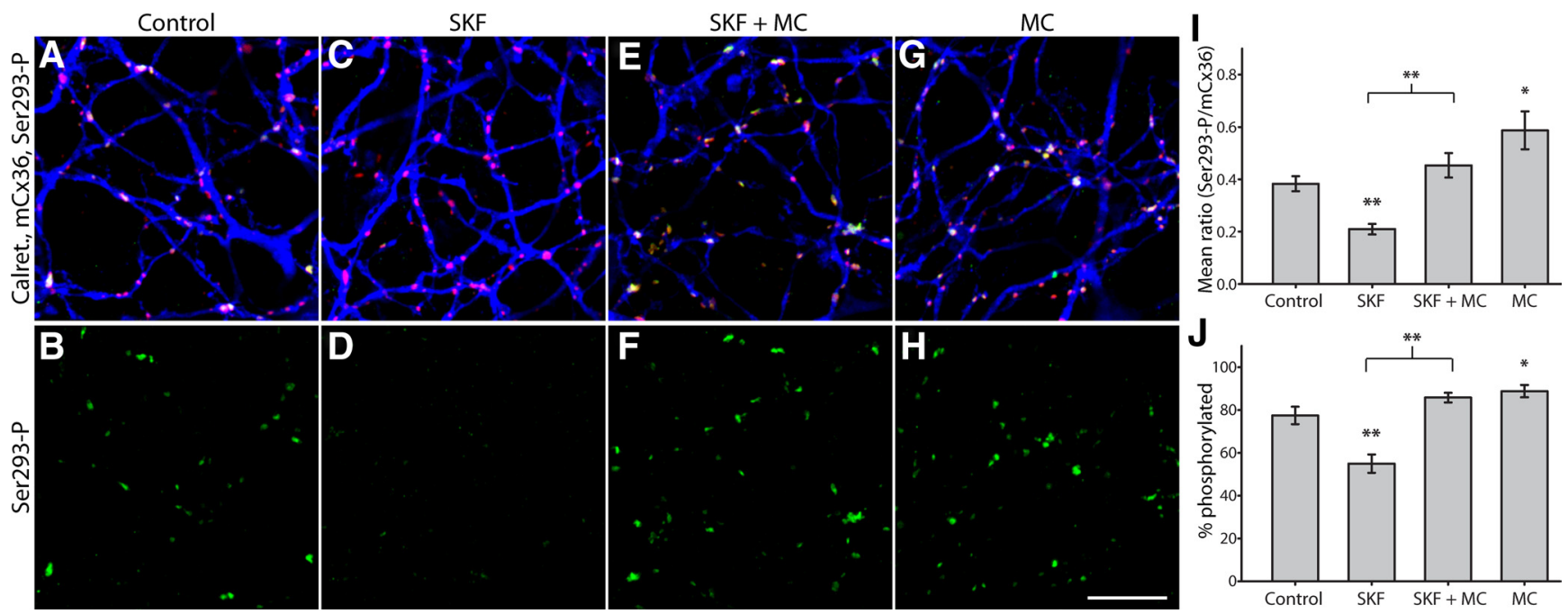

Figure 4. PP2A is required for $D_{1} R$-dependent dephosphorylation of $C \times 36$ at Ser293 in All amacrine cells. $A, B$, Control; color scheme and antibodies are the same as Figure 2. C, D, $D_{1} R$ activation [SKF38393 (SKF), $10 \mu \mathrm{M}$ ] greatly diminished Ser293-P labeling. $E$, $F$, Inhibition of PP2A [microcystin-LR (MC), $0.5 \mathrm{~nm}$ ] completely blocked the reduction in Ser293 phosphorylation caused by $D_{1} R$ activation. G, H, Inhibition of PP2A alone led to increased phosphorylation of Ser293. I, Summary of data shows that inhibition of PP2A significantly blocked the reduction in Ser293 phosphorylation caused by $D_{1} R$ activation and that PP2A inhibition alone significantly increased Ser293 phosphorylation. J, Summary of data shows that changes in the percentage of $C \times 36$ plaques that show detectable Ser293-P labeling follows the same pattern established for relative Ser293-P measurements in I. Error bars are SEM, $n=6 .{ }^{*} p<0.05$, ${ }^{* *} p<0.01$. Images are 1- $\mu \mathrm{m}$-deep stacks. Scale bar: $\boldsymbol{H}, 10 \mu \mathrm{m}$.
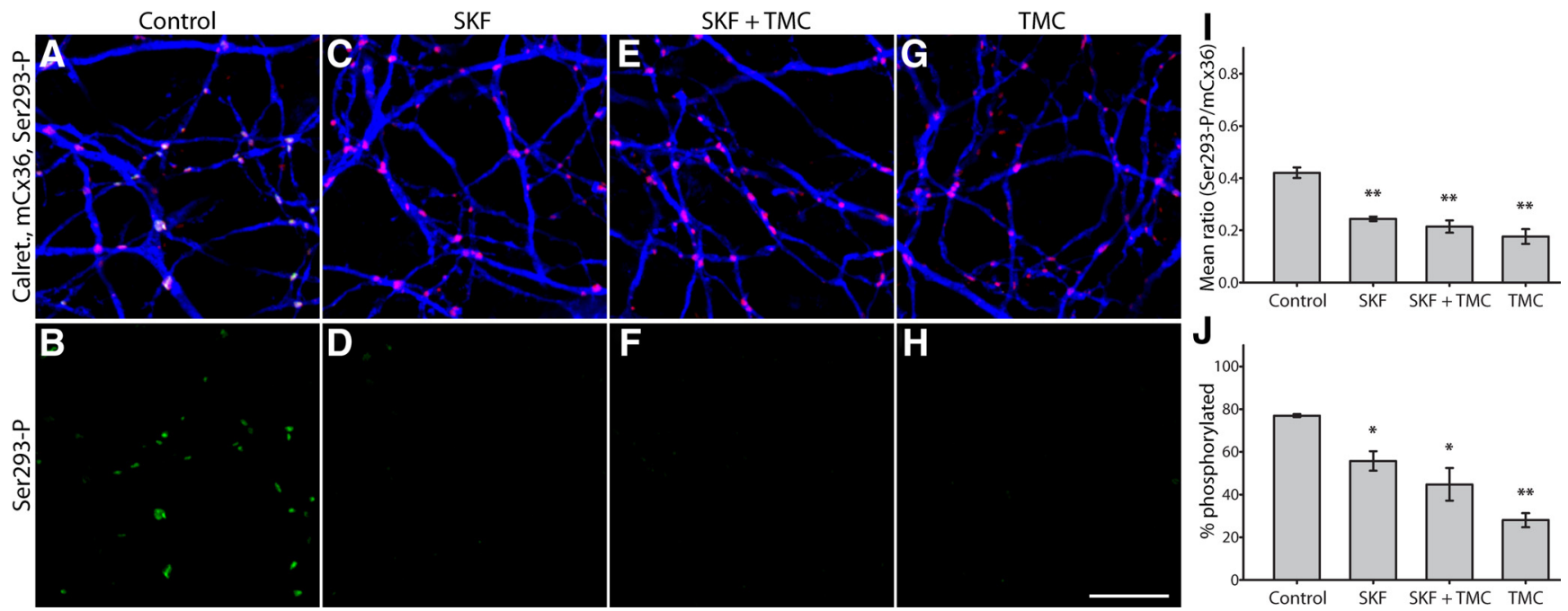

Figure 5. PP1 negatively regulates the dephosphorylation of (X36. A, B, Control; color scheme and antibodies are the same as Figure 2. C, D, D, R activation [SKF38393 (SKF), $10 \mu \mathrm{M}]$ greatly diminished Ser293-P labeling. $\boldsymbol{E}, \boldsymbol{F}$, Inhibition of PP1 [tautomycetin (TMC), $10 \mathrm{~nm}$ ] did not alter the effects of $D_{1} R$ activation. $\boldsymbol{G}, \boldsymbol{H}$, Inhibition of PP1 alone was sufficient to cause a strong reduction in Ser293-P labeling. $I$, Summary of data shows that inhibition of PP1 did not prevent the reduction in Ser293 phosphorylation caused by $D_{1} R$ activation and that PP1 inhibition alone significantly reduced Ser293 phosphorylation.J, Summary of data shows that changes in the percentage of $\mathrm{X} 36$ plaques that show detectable Ser293-P labeling follows the same pattern established for relative Ser293-P measurements in $I$. Error bars are SEM, $n=4 .{ }^{*} p<0.05,{ }^{* *} p<0.01$. Images are $1-\mu \mathrm{m}$-deep stacks. Scale bar: $\boldsymbol{H}, 10 \mu \mathrm{m}$.

similar to the effect of $\mathrm{D}_{1} \mathrm{R}$ antagonist application. Contrasting these results, tautomycetin (10 nM), an inhibitor with higher affinity for PP1 ( $\mathrm{IC}_{50}$ of $\left.1.6 \mathrm{nM}\right)$ than for PP2A ( $\mathrm{IC}_{50}$ of $\left.62 \mathrm{nM}\right)$ (Mitsuhashi et al., 2001), did not prevent the $\mathrm{D}_{1} \mathrm{R}$-mediated reduction of Ser293-P (Fig. 5F). Interestingly, inhibition of PP1 with tautomycetin in the absence of D1R activation was sufficient to cause a robust reduction in Ser293-P (Fig. 5H). As shown in the previous experiments, the percentage of $\mathrm{Cx} 36$ plaques showing detectable Ser293-P labeling followed the same pattern revealed by measuring the mean Ser293-P for both PP2A and PP1 inhibitors (Figs. $4 \mathrm{~J}, 5 \mathrm{~J}$ ). These results provide a measure of confidence that the concentrations of microcystin-LR and tautomycetin used were selective for PP2A and PP1, respectively, because only microcystin-LR was able to block the effects of $\mathrm{D}_{1} \mathrm{R}$ activation and because they had opposite effects on Cx36 phosphorylation when applied alone. Together, these experiments argue that PP2A is a necessary component of the $\mathrm{D}_{1} \mathrm{R}$ pathway regulating Cx36 phosphorylation and coupling strength between AII amacrine cells, and these results are consistent with direct dephosphorylation of Ser293 by PP2A. These experiments also provide evidence that PP1 is involved in regulating Cx36-mediated coupling of AII amacrine cells. However, these results are not consistent with PP1 acting directly on Ser293. Rather, they indicate that PP1 negatively regulates the pathway leading to dephosphorylation of Ser293, although the exact mechanism for this action is unclear. 

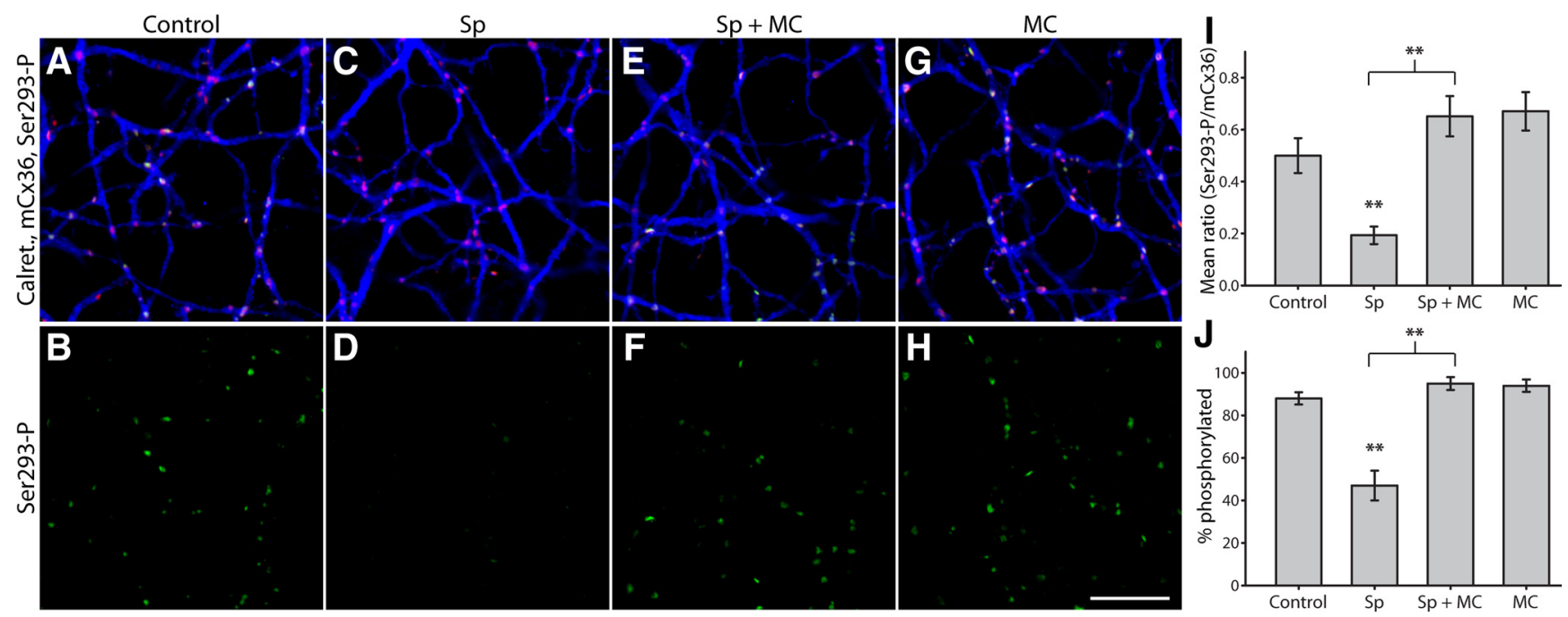

Figure 6. PP2A is required for PKA-dependent dephosphorylation of $\mathrm{Cx} 36$ at Ser293 in All amacrine cells. $A, \boldsymbol{B}$, Control; color scheme and antibodies are the same as Figure 2. C, D, PKA activation [Sp-8-CPT-CAMPS (Sp), $20 \mu \mathrm{M}$ ] greatly diminished Ser293-P labeling, just as $D_{1} R$ activation did. $\boldsymbol{E}, \boldsymbol{F}$, Inhibition of PP2A [microcystin-LR (MC), $0.5 \mathrm{~nm}$ ] completely blocked the reduction in Ser293 phosphorylation caused by PKA activation. $\mathbf{G}, \boldsymbol{H}$, Inhibition of PP2A alone slightly increased Ser293 phosphorylation relative to control. I, Summary of data shows that inhibition of PP2A significantly blocked the reduction in Ser293 phosphorylation caused by PKA activation. We observed a trend toward increased Ser293 phosphorylation when PP2A alone was inhibited, similar to the significant

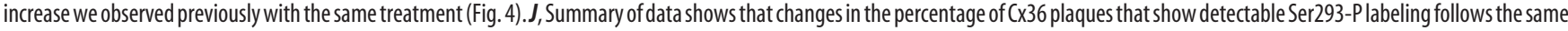
pattern established for relative Ser293-P measurements in $\boldsymbol{I}$. Error bars are SEM, $n=5 .{ }^{* *} p<0.01$. Images are 1- $\mu \mathrm{m}$-deep stacks. Scale bar: $\boldsymbol{H}, 10 \mu \mathrm{m}$.

\section{PKA drives PP2A-mediated dephosphorylation of Cx36}

Based on the results showing that both PKA and PP2A are downstream of $D_{1} R$ activation, we next asked whether PP2A itself is activated by PKA in AII amacrine cells. Such a pathway has been described recently in medium-sized, spiny neurons in the striatum, in which $\mathrm{D}_{1}$ R-stimulated activation of PKA causes phosphorylation of the regulatory subunit of PP2A and thus increases the activity of the phosphatase (Ahn et al., 2007). These striatal neurons bear certain similarities to AII amacrine cells (namely, $\mathrm{D}_{1} \mathrm{R}$ and DARPP-32 expression) (Partida et al., 2004; Svenningsson et al., 2004; Witkovsky et al., 2007). To test this hypothesis, we bypassed $\mathrm{D}_{1}$ Rs and directly stimulated PKA. PKA activation (Sp8-CPT-cAMPS, $20 \mu \mathrm{M}$ ) strongly reduced mean Ser293-P in AII amacrine cells (Fig. $6 D$ ), just as $D_{1} R$ activation did. Inhibition of PP2A (microcystin-LR, $0.5 \mathrm{nM}$ ) completely blocked the PKAmediated reduction in Ser293-P (Fig. 6F). Inhibition of PP2A alone caused a trend toward increased phosphorylation of Ser293-P (Fig. 6I), similar to the significant increase noted above (Fig. 4). As before, the percentage of $\mathrm{Cx} 36$ plaques showing detectable phospho-antibody labeling followed the same pattern established by measuring the mean Ser293-P intensity (Fig. 6J). These results confirm that PP2A is required for PKA-dependent dephosphorylation of $\mathrm{Cx} 36$ in AII amacrine cells and support the existence of the $\mathrm{D}_{1} \mathrm{R} \rightarrow$ PKA $\rightarrow$ PP2A pathway in these neurons.

\section{Phosphorylation of $\mathrm{Cx} 36$ is controlled independently at each gap junction plaque}

We frequently observed that $\mathrm{Cx} 36$ gap junctions in close proximity of each other existed in very different phosphorylation states, even across gap junctions positioned along a single dendrite. This was most apparent in control conditions (Fig. $2 A, B$, arrowheads). Pharmacologic activation of $\mathrm{D}_{1}$ Rs reduced the heterogeneity observed in Ser293-P by causing a strong reduction in the relative degree of phosphorylation at each Cx36 plaque. Conversely, antagonism of $\mathrm{D}_{1}$ Rs led to an increase in the relative degree of phosphorylation at each $\mathrm{Cx} 36$ plaque, indicating that dopamine-driven dephosphorylation of Cx36 is opposed by an unknown process. Thus, it appears that our control condition represents a near-equilibrium point, in which conditions at some gap junction plaques favor phosphorylation of Cx36 and conditions at others favor dephosphorylation of $\mathrm{Cx} 36$. The observation that this variation exists even for pairs of $\mathrm{Cx} 36$ plaques within 1 $\mu \mathrm{m}$ of one another suggests that each Cx36 gap junction plaque functions as an individual unit, the regulation of which is at least partially controlled by very local processes.

Overall, we have quantitatively demonstrated the relationship between AII amacrine cell uncoupling and Cx36 dephosphorylation. Our results describe a $\mathrm{D}_{1} \mathrm{R} \rightarrow \mathrm{PKA} \rightarrow \mathrm{PP} 2 \mathrm{~A}$ pathway that mediates the dephosphorylation of Cx36 at Ser293 and thus the $\mathrm{D}_{1} \mathrm{R}$-mediated uncoupling of AII amacrine cells (Fig. 7). PP1 activity negatively regulates this dephosphorylation pathway at an unknown point. Our results indicate that regulation is likely controlled at the level of individual Cx36 plaques and that phosphorylation of Ser293 appears to influence permeability of these gap junctions but not the trafficking of $\mathrm{C} \times 36$.

\section{Discussion}

One fundamental function of the retina is to adapt to fluctuating background illumination. Electrical coupling between AII amacrine cells increases the signal-to-noise ratio of their response to light (Vardi and Smith, 1996; Dunn et al., 2006). Modulation of coupling strength between AII amacrine cells serves to optimize signal-to-noise ratio for prevailing background illumination and is one mechanism the retina uses to accomplish luminance adaptation (Bloomfield and Völgyi, 2004). In darkness, AIIs are relatively uncoupled, thus preserving single-photon responses in a small group of AIIs. Coupling increases greatly under low scotopic to mesopic illumination, allowing for summation of coincident signals and improved signal-to-noise ratio. The AII network is uncoupled under photopic illumination by dopamine signaling. This may act to prevent contamination of cone photoreceptor signals in cone bipolar cells by saturated rod signals in AII amacrine cells. In addition, AIIs provide inhibitory glycinergic input to Off cone bipolar cells (Strettoi et al., 1992) and some 


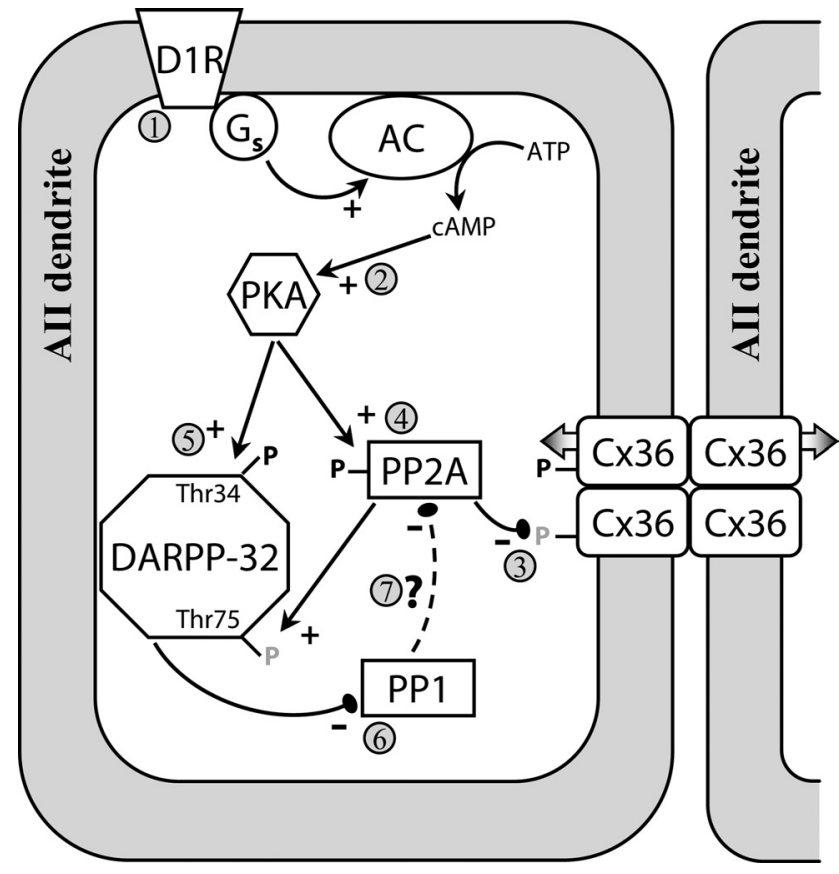

Figure 7. Model of $D_{1} R$-dependent regulation of $(x 36$-mediated coupling between All amacrine cells. Activation of $D_{1} R s$ (1) initiates a cascade leading to activation of PKA (2); both $D_{1} R$ and PKA activation are sufficient to uncouple All amacrine cells (Hampson et al., 1992; Mills and Massey, 1995). In this study, we showed that $D_{1}$ R-dependent dephosphorylation (gray P) of Ser293 on (x36 uncouples All amacrine cells (3). We show that PP2A is required for both $D_{1} R$ - and PKA-stimulated dephosphorylation of $S$ er293 (4). This provides evidence that the $D_{1} R \rightarrow P K A \rightarrow P P 2 A$ pathway, which was recently described in spiny neurons in the striatum and led to dephosphorylation of Thr75 on DARPP-32 (Ahn et al., 2007), is also present in the All amacrine cell. All amacrine cells also express DARPP-32 (Partida et al., 2004; Witkovsky et al., 2007), and dephosphorylation of Thr75 on DARPP-32 facilitates PKA-mediated phosphorylation (black P) of Thr34 (5), which converts DAPRR-32 into an inhibitor of PP1 (6) (Svenningsson et al., 2004). We found that PP1 negatively regulates the dephosphorylation of $\mathrm{C} x 36$, possibly by opposing PKA-mediated activation of PP2A (7). Our results indicate that the $D_{1} R \rightarrow P K A \rightarrow P P 2 A$ pathway is not limited to striatal neurons and may represent a common pathway in neurons expressing $D_{1} R$ s and DARPP-32.

Off ganglion cells (Manookin et al., 2008; Murphy and Rieke, 2008; Münch et al., 2009). Thus, uncoupling of the AII network should also act to increase the spatial resolution of On cone bipolar cell-driven feedforward inhibition of Off cone bipolar and retinal ganglion cells.

Previously, it was unclear what molecular mechanism modulates coupling through Cx36 gap junctions. Although increased phosphorylation of $\mathrm{Cx} 36$ has been implicated as a mechanism for uncoupling gap junctions based on the dependence on PKA activity (Ouyang et al., 2005; Urschel et al., 2006), this has not been directly assessed. By making quantitative measures of tracer diffusion between AII amacrine cells and the relative phosphorylation of Cx36 gap junctions between these cells, we have determined that dephosphorylation of Ser293 is associated with uncoupling of the AII amacrine cell network. Decreases in both coupling and phosphorylation are triggered by dopamine $D_{1} R$ signaling and are mediated (at least in part) by activation of PKA. This finding, together with the previous finding that the Ser293 phosphorylation site is one of two that are required for regulation of Cx36 coupling by PKA activity (Ouyang et al., 2005), provides strong evidence that dephosphorylation of Cx36 at Ser293 is the mechanism by which Cx36 gap junctions are uncoupled.

It has been reported that SCH23390 $(10 \mu \mathrm{M})$ blocks the uncoupling effect of exogenous dopamine (100 nM) application (Hampson et al., 1992). It is thus curious that, in our hands, 10 $\mu \mathrm{M}$ SCH23390 did not alter AII amacrine cell coupling, but 100 $\mu \mathrm{M}$ SCH23390 increased coupling. However, technical differences between our tracer coupling measurements and those made in the previous study preclude direct comparison. Hampson et al. (1992) used a more sensitive but nonlinear (peroxidase amplification) tracer detection method and threefold to fourfold longer diffusion periods, potentially amplifying small effects. It is difficult to precisely identify the reason that a high concentration of SCH23390 was required to increase coupling in our experiments. It is possible that the nonspecific binding of the drug to other targets with low-affinity binding sites (Leonard et al., 2006; Ekelund et al., 2007) caused network effects that led to increased AII amacrine cell coupling. However, given that both the $\mathrm{D}_{1} \mathrm{R}$ agonist SKF38393 $(10 \mu \mathrm{M})$ and dopamine $(1 \mu \mathrm{M})$ effectively drove reductions in AII amacrine cell coupling, the specific action of $\mathrm{SCH} 23390$ on $\mathrm{D}_{1}$-like dopamine receptors seems most likely.

The molecular mechanism by which phosphorylation of Ser293 alters coupling through Cx36 gap junctions is still a topic for additional study. We have excluded changes in the trafficking of $\mathrm{Cx} 36$ proteins and reduction in the absolute number of $\mathrm{Cx} 36$ gap junctions on AII amacrine cells as potential mechanisms by which dephosphorylation of $\mathrm{Cx} 36$ reduces coupling. Thus, it seems likely that dephosphorylation of $\mathrm{Cx} 36$ reduces its permeability to the Neurobiotin tracer. The question of what dephosphorylation of $\mathrm{Cx} 36$ does to the single-channel conductance and/or open probability or open duration of the channel is of more biological significance in neurons. Although our experiments here cannot directly address this measure of channel function, it has been shown recently that the junctional conductance between pairs of AII amacrine cells can change dynamically up to sixfold (Veruki et al., 2008). This increase was time dependent and was observed with low-resistance patch pipettes but not with high-resistance pipettes, leading the authors to suggest that the increase in coupling was attributable to gradual washout of an endogenous regulatory system in the AII amacrine cell. Washout of cAMP is the most prominent initial candidate and should result in a gradual increase in the phosphorylation of $\mathrm{Cx} 36$.

Our results indicate that the $\mathrm{D}_{1} \mathrm{R}$ - and PKA-dependent dephosphorylation of $\mathrm{Cx} 36$ in AII amacrine cells requires PP2A activation. $\mathrm{A} \mathrm{D}_{1} \mathrm{R} \rightarrow \mathrm{PKA} \rightarrow \mathrm{PP} 2 \mathrm{~A}$ pathway also exists in medium-sized spiny neurons of the striatum, in which Thr75 of DARPP-32 (dopamine and cAMP-regulated phosphoprotein) is one substrate for PP2A (Ahn et al., 2007). This dephosphorylation allows PKA to phosphorylate Thr34 of DARPP-32, thereby converting it into a potent inhibitor of PP1 (Svenningsson et al., 2004). DARPP-32 is also expressed by AII amacrine cells (Partida et al., 2004; Witkovsky et al., 2007), and we show that, although PP1 inhibition does not mediate $\mathrm{D}_{1} \mathrm{R}$-stimulated dephosphorylation of Cx36, PP1 inhibition alone is sufficient to cause Ser293 dephosphorylation. Because PKA activation of PP2A in the striatal spiny neuron was caused by phosphorylation of the regulatory subunit of PP2A (Ahn et al., 2007), one explanation for our finding is that PP1 activity may oppose PKA-dependent activation of PP2A by phosphorylation (Fig. 7), although we did not explicitly test this hypothesis. It is clear from our results that the dopamine $\mathrm{D}_{1} \mathrm{R} \rightarrow \mathrm{PKA} \rightarrow \mathrm{PP} 2 \mathrm{~A}$ pathway is not limited to the striatal neurons in which it was first described but is also a component of dopamine signaling in other neurons, such as the AII amacrine cell.

In the retina, dopamine signaling originates from dopaminergic amacrine cells and is associated with light adaptation (Witkovsky, 2004). In addition to the AII amacrine cell, dopa- 
mine modulates the coupling state of other Cx36-coupled retinal neurons, such as cone photoreceptors (Lee et al., 2003; O'Brien et al., 2004; Zhang and Wu, 2004; Ribelayga et al., 2008) and OFF $\alpha$ ganglion cells (Hidaka et al., 2002; Mills et al., 2007). In both of these cases, however, activation of $\mathrm{D}_{2}$-like dopamine receptors triggers the uncoupling. This suggests that, in cones and OFF $\alpha$ ganglion cells, reduced $[\mathrm{cAMP}]_{\mathrm{i}}$ and reduced PKA activity mediate uncoupling. Based on the relationship between Cx36 phosphorylation and AII amacrine coupling strength that we describe here, we would predict that, in cones and OFF $\alpha$ ganglion cells, PKA acts directly on $\mathrm{Cx} 36$ proteins rather than activating a phosphatase effector, and in cones this appears to be the case (Li et al., 2009). Previous reports support this possibility, because we and others have shown that PKA can directly phosphorylate regulatory residues on Cx36 in vitro (Ouyang et al., 2005; Urschel et al., 2006; Kothmann et al., 2007). Thus, regulation of Cx36-mediated coupling is specific to individual neuronal subtypes in the retina and is dependent on the signaling pathways they express.

The specificity of regulation that we observe in retinal neurons indicates that the signaling pathways that control coupling are likely to vary in other Cx36-coupled networks, such as those found in cortex, hippocampus, cerebellum, inferior olive, and elsewhere. For instance, several kinases converge onto the regulatory phosphorylation sites of $\mathrm{Cx} 36$ in vitro, including PKA, PKG, and CaMKII (Ouyang et al., 2005; Patel et al., 2006; Urschel et al., 2006; Kothmann et al., 2007; Alev et al., 2008), suggesting that many common signaling pathways can modulate coupling. The importance of regulation of Cx36-mediated coupling in other networks is currently not well understood, because most studies have focused on the consequences of complete loss of Cx36-mediated coupling (Deans et al., 2001; Buhl et al., 2003; Van Der Giessen et al., 2008). The results we present here provide a framework for future study of coupling in these systems, in which increased phosphorylation of Ser293 indicates increased coupling and vice versa.

We commonly observed heterogeneity of Cx36 phosphorylation within individual AII amacrine cells under control conditions. This observation implies that $\mathrm{Cx} 36$ phosphorylation, and thus coupling, is controlled at the level of individual gap junction plaques. This possibility evokes comparisons with the postsynaptic density found at chemical synapses, in which complexes of signaling proteins are assembled and provide synapse-specific modulation of important synaptic elements, such as glutamate receptors (Soderling and Derkach, 2000; Feng and Zhang, 2009). The C-terminal tail of Cx36 binds PDZ (postsynaptic density-95/ Discs large/zona occludens-1) domain-containing proteins ( $\mathrm{Li}$ et al., 2004) and may bind some of the same molecules that form the scaffolding complex at the postsynaptic density. Additionally, CaMKII can bind directly to Cx36 (Alev et al., 2008), providing the means for localization of one potential regulator of coupling.

Local control of coupling would allow for the possibility of activity-dependent regulation of individual electrical synapses. This is particularly interesting to consider in the case of the AII amacrine cell, which shifts from uncoupled in dark-adapted retina to well coupled through most of the scotopic range of vision and which finally becomes uncoupled again under photopic visual conditions (Bloomfield and Völgyi, 2004) as a result of dopamine signaling. What causes the increase in coupling when background illumination increases from darkness to scotopic levels? One possibility is that glutamate release from rod bipolar cells causes $\mathrm{Ca}^{2+}$ influx in the AII dendrites, leading to activation of CaMKII and phosphorylation of Cx36, thus increasing coupling in a manner dependent on presynaptic activity. There are several potential sources of $\mathrm{Ca}^{2+}$ on AII dendrites, including $\mathrm{Ca}^{2+}$-permeable AMPA receptors and NMDA receptors (Hartveit and Veruki, 1997; Mørkve et al., 2002). One possible role for locally increasing coupling in an activity-dependent manner is to allow the spread and summation of signals from active rod bipolar cells in AII amacrine cells when photon catch is very low (near visual threshold). Gap junctions not in the vicinity of an active rod bipolar cell would remain uncoupled and thus reduce the sharing of noisy fluctuations in the AII membrane potential. This could be particularly important in AIIs, which are inherently noisy because of the nature of the rod bipolar to AII amacrine synaptic inputs (Dunn et al., 2006). As background light intensity increases in the scotopic range, additional rod bipolar cells will become active and continue to increase AII amacrine cell coupling, as has been described previously (Bloomfield and Völgyi, 2004).

\section{References}

Ahn JH, McAvoy T, Rakhilin SV, Nishi A, Greengard P, Nairn AC (2007) Protein kinase A activates protein phosphatase $2 \mathrm{~A}$ by phosphorylation of the B56delta subunit. Proc Natl Acad Sci U S A 104:2979-2984.

Alev C, Urschel S, Sonntag S, Zoidl G, Fort AG, Höher T, Matsubara M, Willecke K, Spray DC, Dermietzel R (2008) The neuronal connexin36 interacts with and is phosphorylated by CaMKII in a way similar to CaMKII interaction with glutamate receptors. Proc Natl Acad Sci U S A 105:20964-20969.

Bloomfield SA, Völgyi B (2004) Function and plasticity of homologous coupling between AII amacrine cells. Vision Res 44:3297-3306.

Bloomfield SA, Völgyi B (2009) The diverse functional roles and regulation of neuronal gap junctions in the retina. Nat Rev Neurosci 10:495-506.

Bloomfield SA, Xin D, Osborne T (1997) Light-induced modulation of coupling between AII amacrine cells in the rabbit retina. Vis Neurosci 14:565-576.

Buhl DL, Harris KD, Hormuzdi SG, Monyer H, Buzsáki G (2003) Selective impairment of hippocampal gamma oscillations in connexin-36 knockout mouse in vivo. J Neurosci 23:1013-1018.

Connors BW (2009) Electrical signaling with neuronal gap junctions. In: Connexins: a guide (Harris AL, Locke D, eds), pp 143-164. New York, NY: Humana.

Deans MR, Gibson JR, Sellitto C, Connors BW, Paul DL (2001) Synchronous activity of inhibitory networks in neocortex requires electrical synapses containing connexin36. Neuron 31:477-485.

Deans MR, Volgyi B, Goodenough DA, Bloomfield SA, Paul DL (2002) Connexin36 is essential for transmission of rod-mediated visual signals in the mammalian retina. Neuron 36:703-712.

DeVries SH, QiX, Smith R, Makous W, Sterling P (2002) Electrical coupling between mammalian cones. Curr Biol 12:1900-1907.

Dunn FA, Doan T, Sampath AP, Rieke F (2006) Controlling the gain of rod-mediated signals in the mammalian retina. J Neurosci 26:3959-3970.

Ekelund J, Slifstein M, Narendran R, Guillin O, Belani H, Guo NN, Hwang Y, Hwang DR, Abi-Dargham A, Laruelle M (2007) In vivo DA $D_{1}$ receptor selectivity of NNC 112 and SCH 23390. Mol Imaging Biol 9:117-125.

Famiglietti EV Jr, Kolb H (1975) A bistratified amacrine cell and synaptic cirucitry in the inner plexiform layer of the retina. Brain Res 84:293-300.

Feigenspan A, Teubner B, Willecke K, Weiler R (2001) Expression of neuronal connexin36 in AII amacrine cells of the mammalian retina. J Neurosci 21:230-239.

Feng W, Zhang M (2009) Organization and dynamics of PDZ-domainrelated supramodules in the postsynaptic density. Nat Rev Neurosci 10:87-99.

Güldenagel M, Ammermüller J, Feigenspan A, Teubner B, Degen J, Söhl G, Willecke K, Weiler R (2001) Visual transmission deficits in mice with targeted disruption of the gap junction gene connexin36. J Neurosci 21:6036-6044.

Hampson EC, Vaney DI, Weiler R (1992) Dopaminergic modulation of gap junction permeability between amacrine cells in mammalian retina. J Neurosci 12:4911-4922.

Hartveit E, Veruki ML (1997) AII amacrine cells express functional NMDA receptors. Neuroreport 8:1219-1223. 
Hidaka S, Kato T, Miyachi E (2002) Expression of gap junction connexin36 in adult rat retinal ganglion cells. J Integr Neurosci 1:3-22.

Honkanen RE, Zwiller J, Moore RE, Daily SL, Khatra BS, Dukelow M, Boynton AL (1990) Characterization of microcystin-LR, a potent inhibitor of type 1 and type 2A protein phosphatases. J Biol Chem 265:19401-19404.

Hormuzdi SG, Pais I, LeBeau FE, Towers SK, Rozov A, Buhl EH, Whittington MA, Monyer H (2001) Impaired electrical signaling disrupts gamma frequency oscillations in connexin 36-deficient mice. Neuron 31:487-495.

Kothmann WW, Li X, Burr GS, O’Brien J (2007) Connexin 35/36 is phosphorylated at regulatory sites in the retina. Vis Neurosci 24:363-375.

Lee EJ, Han JW, Kim HJ, Kim IB, Lee MY, Oh SJ, Chung JW, Chun MH (2003) The immunocytochemical localization of connexin 36 at rod and cone gap junctions in the guinea pig retina. Eur J Neurosci 18:2925-2934.

Leonard SK, Ferry-Leeper P, Mailman RB (2006) Low affinity binding of the classical D1 antagonist SCH23390 in rodent brain: potential interaction with A2A and D2-like receptors. Brain Res 1117:25-37.

Li H, Chuang AZ, O'Brien J (2009) Photoreceptor coupling is controlled by connexin 35 phosphorylation in zebrafish retina. J Neurosci, in press.

Li X, Olson C, Lu S, Kamasawa N, Yasumura T, Rash JE, Nagy JI (2004) Neuronal connexin36 association with zonula occludens-1 protein (ZO-1) in mouse brain and interaction with the first PDZ domain of ZO-1. Eur J Neurosci 19:2132-2146.

Manookin MB, Beaudoin DL, Ernst ZR, Flagel LJ, Demb JB (2008) Disinhibition combines with excitation to extend the operating range of the OFF visual pathway in daylight. J Neurosci 28:4136-4150.

Mills SL, Massey SC (1991) Labeling and distribution of AII amacrine cells in the rabbit retina. J Comp Neurol 304:491-501.

Mills SL, Massey SC (1995) Differential properties of two gap junctional pathways made by AII amacrine cells. Nature 377:734-737.

Mills SL, O’Brien JJ, Li W, O'Brien J, Massey SC (2001) Rod pathways in the mammalian retina use connexin 36. J Comp Neurol 436:336-350.

Mills SL, Xia XB, Hoshi H, Firth SI, Rice ME, Frishman LJ, Marshak DW (2007) Dopaminergic modulation of tracer coupling in a ganglionamacrine cell network. Vis Neurosci 24:593-608.

Mitsuhashi S, Matsuura N, Ubukata M, Oikawa H, Shima H, Kikuchi K (2001) Tautomycetin is a novel and specific inhibitor of serine/threonine protein phosphatase type 1, PP1. Biochem Biophys Res Commun 287:328-331.

Mørkve SH, Veruki ML, Hartveit E (2002) Functional characteristics of non-NMDA-type ionotropic glutamate receptor channels in AII amacrine cells in rat retina. J Physiol 542:147-165.

Münch TA, da Silveira RA, Siegert S, Viney TJ, Awatramani GB, Roska B (2009) Approach sensitivity in the retina processed by a multifunctional neural circuit. Nat Neurosci 12:1308-1316.

Murphy GJ, Rieke F (2008) Signals and noise in an inhibitory interneuron diverge to control activity in nearby retinal ganglion cells. Nat Neurosci 11:318-326.

Neve KA, Seamans JK, Trantham-Davidson H (2004) Dopamine receptor signaling. J Recept Signal Transduct Res 24:165-205.

O’Brien J, Nguyen HB, Mills SL (2004) Cone photoreceptors in bass retina use two connexins to mediate electrical coupling. J Neurosci 24:56325642.

Ouyang X, Winbow VM, Patel LS, Burr GS, Mitchell CK, O’Brien J (2005) Protein kinase A mediates regulation of gap junctions containing connexin35 through a complex pathway. Brain Res Mol Brain Res 135:1-11.

Partida GJ, Lee SC, Haft-Candell L, Nichols GS, Ishida AT (2004) DARPP32-like immunoreactivity in AII amacrine cells of rat retina. J Comp Neurol 480:251-263.

Patel LS, Mitchell CK, Dubinsky WP, O’Brien J (2006) Regulation of gap junction coupling through the neuronal connexin Cx35 by nitric oxide and cGMP. Cell Commun Adhes 13:41-54.

Ribelayga C, Cao Y, Mangel SC (2008) The circadian clock in the retina controls rod-cone coupling. Neuron 59:790-801.

Serre-Beinier V, Bosco D, Zulianello L, Charollais A, Caille D, Charpantier E, Gauthier BR, Diaferia GR, Giepmans BN, Lupi R, Marchetti P, Deng S, Buhler L, Berney T, Cirulli V, Meda P (2008) Cx36 makes channels coupling human pancreatic $\beta$-cells, and correlates with insulin expression. Hum Mol Genet 18:428-439.

Soderling TR, Derkach VA (2000) Postsynaptic protein phosphorylation and LTP. Trends Neurosci 23:75-80.

Strettoi E, Dacheux RF, Raviola E (1990) Synaptic connections of rod bipolar cells in the inner plexiform layer of the rabbit retina. J Comp Neurol 295:449-466.

Strettoi E, Raviola E, Dacheux RF (1992) Synaptic connections of the narrow-field, bistratified rod amacrine cell (AII) in the rabbit retina. J Comp Neurol 325:152-168.

Svenningsson P, Nishi A, Fisone G, Girault JA, Nairn AC, Greengard P (2004) DARPP-32: an integrator of neurotransmission. Annu Rev Pharmacol Toxicol 44:269-296.

Urschel S, Höher T, Schubert T, Alev C, Söhl G, Wörsdörfer P, Asahara T, Dermietzel R, Weiler R, Willecke K (2006) Protein kinase A-mediated phosphorylation of connexin36 in mouse retina results in decreased gap junctional communication between AII amacrine cells. J Biol Chem 281:33163-33171.

Van Der Giessen RS, Koekkoek SK, van Dorp S, De Gruijl JR, Cupido A, Khosrovani S, Dortland B, Wellershaus K, Degen J, Deuchars J, Fuchs EC, Monyer H, Willecke K, De Jeu MT, De Zeeuw CI (2008) Role of olivary electrical coupling in cerebellar motor learning. Neuron 58:599-612.

Vardi N, Smith RG (1996) The AII amacrine network: coupling can increase correlated activity. Vision Res 36:3743-3757.

Veruki ML, Hartveit E (2002) AII (Rod) amacrine cells form a network of electrically coupled interneurons in the mammalian retina. Neuron 33:935-946.

Veruki ML, Oltedal L, Hartveit E (2008) Electrical synapses between AII amacrine cells: dynamic range and functional consequences of variation in junctional conductance. J Neurophysiol 100:3305-3322.

Virshup DM, Shenolikar S (2009) From promiscuity to precision: protein phosphatases get a makeover. Mol Cell 33:537-545.

Völgyi B, Deans MR, Paul DL, Bloomfield SA (2004) Convergence and segregation of the multiple rod pathways in mammalian retina. J Neurosci 24:11182-11192.

Wellershaus K, Degen J, Deuchars J, Theis M, Charollais A, Caille D, Gauthier B, Janssen-Bienhold U, Sonntag S, Herrera P, Meda P, Willecke K (2008) A new conditional mouse mutant reveals specific expression and functions of connexin 36 in neurons and pancreatic beta-cells. Exp Cell Res 314:997-1012.

Witkovsky P (2004) Dopamine and retinal function. Doc Ophthalmol 108:17-40.

Witkovsky P, Nicholson C, Rice ME, Bohmaker K, Meller E (1993) Extracellular dopamine concentration in the retina of the clawed frog, Xenopus laevis. Proc Natl Acad Sci U S A 90:5667-5671.

Witkovsky P, Svenningsson P, Yan L, Bateup H, Silver R (2007) Cellular localization and function of DARPP-32 in the rodent retina. Eur J Neurosci 25:3233-3242.

Xia XB, Mills SL (2004) Gap junctional regulatory mechanisms in the AII amacrine cell of the rabbit retina. Vis Neurosci 21:791-805.

Zhang J, Wu SM (2004) Connexin35/36 gap junction proteins are expressed in photoreceptors of the tiger salamander retina. J Comp Neurol 470:1-12. 